\title{
Eikenella corrodens endocarditis and liver abscess in a previously healthy male, a case report
}

\author{
Anne Christine Nordholm ${ }^{1 *}$ (D), Ruth Ottilia Birgitta Vøgg ${ }^{1,3}$, Henrik Permin $^{2}$ and Terese Katzenstein ${ }^{1}$
}

\begin{abstract}
Background: Eikenella corrodens is one of the HACEK bacteria constituting part of the normal flora of the oropharynx, however, still an uncommon pathogen. We report a case of a large Eikenella corrodens liver abscess with simultaneously endocarditis in a previously healthy male.

Case presentation: A 49-year-old Danish man was admitted because of one-month malaise, fever, cough and unintentional weight loss. On admission there was elevated white blood cell count and C-reactive protein, as well as affected liver function tests. Initially pneumonia was suspected, but due to lack of improvement on pneumonia treatment, a PET-CT scan was performed, which showed a large multiloculated abscess in the liver. The abscess was drained using ultrasound guidance. Culture demonstrated Eikenella corrodens. Transesophageal echocardiography revealed aortic endocarditis. The patient was treated with antibiotics and abscess drainage, on which he slowly improved. He was discharged after 1.5 months of hospitalisation. On follow-up 2 months later, the patient was asymptomatic with normalized biochemistry and ultrasound showed complete regression of the abscess.

Conclusions: This is the first case of documented Eikenella corrodens concurrent liver abscess and endocarditis. The case report highlights that Eikenella corrodens should be considered as a cause of liver abscess. Empirical treatment of pyogenic liver abscess will most often cover Eikenella corrodens, but the recommended treatment is a third generation cephalosporin or a fluoroquinolon. A multiloculated liver abscess may require drainage several times during treatment. The finding of Eikenella corrodens should elicit an echocardiography to diagnose endocarditis even in patients without clinical signs of endocarditis.
\end{abstract}

Keywords: Eikenella corrodens, HACEK, Liver abscess, Endocarditis, Case report

\section{Background}

The HACEK group of bacteria includes Haemophilus parainfluenzae, Aggregatibacter spp., Cardiobacterium spp., Eikenella corrodens and Kingella spp. [1]. These are fastidious gram-negative bacteria that are part of the normal human mucosal flora, predominantly of the oropharynx [2]. HACEK bacteria have traditionally been associated with endocarditis and causes approximately $3 \%$ of all infective endocarditis [3], but blood cultures

\footnotetext{
* Correspondence: anne.christine.nordholm@regionh.dk

Anne Christine Nordholm and Ruth Ottilia Birgitta Vøgg are equal first authors.

Anne Christine Nordholm and Ruth Ottilia Birgitta Vøgg contributed equally to this work.

'Department of Infectious Diseases, Copenhagen University Hospital,

Rigshospitalet, Copenhagen, Denmark

Full list of author information is available at the end of the article
}

are frequently sterile in HACEK endocarditis cases [4]. Eikenella corrodens is the least common cause of HACEK endocarditis and it has only been sporadically described in the literature and often in patients with risk factors [4]; in particular recent dental therapy, intravenous drug abuse, immunosuppression or valvular damage [5]. In the 1970ies it was discovered that Eikenella corrodens could cause visceral abscesses including liver abscesses [6]. Cases of Eikenella corrodens causing liver abscesses have only been reported 12 times in the literature previously [6-17]. Pyogenic liver abscesses (PLA) may result from haematogenous seeding from the systemic circulation, gallstones or malignancies and risk factors include hepatobiliary infection, pancreatic disease, diabetes and prior liver transplant [18]. Treatment often requires both catheter drainage and long-term 
antibiotic treatment [19]. Here, we report a unique case of Eikenella corrodens endocarditis and a large liver abscess in a previously healthy adult male.

\section{Case presentation}

\section{Admission}

A 49-year-old Caucasian male with an unremarkable medical history presented to the emergency department on a local hospital due to a four-week history of malaise, fever, cough and an unintended weight loss of $7 \mathrm{~kg}$. He had no recent travel history or history of drug abuse. Based on the symptoms and stethoscopic findings pneumonia was suspected and the patient was admitted to the Department of Respiratory Diseases. On admission his blood pressure was $135 / 67 \mathrm{mmHg}$, heart rate 125 beats per minute, temperature $36,4{ }^{\circ} \mathrm{C}$, and with an oxygen saturation of $92 \%$ with 21 of oxygen supplementation. On auscultation there were crackles at the right lung, but further clinical examination was unremarkable and he was at no point in acute distress.

\section{Investigations}

Laboratory examination revealed elevated white blood cell count (WBC) at $20 \times 10^{9} / \mathrm{L}$ and C-reactive protein (CRP) at $224 \mathrm{mg} / \mathrm{L}$ along with increased liver function tests (Alanine aminotransferase at $84 \mathrm{U} / \mathrm{L}$ and Alkaline phosphatase at $256 \mathrm{U} / \mathrm{L}$ ) and hypoalbuminemia at $19 \mathrm{~g} / \mathrm{L}$. Chest radiograph showed no obvious infiltrates. Pharyngeal swabs and sputum cultures were negative. Blood and urine cultures came out negative, though collected before the antibiotic treatment was commenced. The blood culture method used was BacT/Alert ${ }^{\circ}$ an- and aerobic collection bottles incubated 5 days and later BD BACTEC Plus an- and aerobic Culture Vials incubated for 7 days. We tested for hepatitis infection; Immunoglobulin (Ig) M for hepatitis A, IgG surface antibody and surface antigen for hepatitis B, IgG for hepatitis $C$ and IgM and IgG for hepatitis $E$ virus (HEV). Of these HEV IgG was positive while the rest all came out negative. In addition, serology tests were negative for Epstein-Barr virus, cytomegalovirus, human immunodeficiency virus, Pneumocystis jirovecii and Entamoeba histolytica. In spite of antibiotic treatment for more than a week (Fig. 2) the patient did not improve, which led to performance of a positron emission tomography-computer tomography (PET-CT) scan in search for the focus of infection. The scan revealed a massive multiloculated abscess $(22 \times 18 \mathrm{~cm})$ (Fig. 1a and b), along with cholelithiasis $(1 \times 1 \mathrm{~cm})$ and lymph nodes enlargement. The following ultrasoundguided abscess catheterisation resulted in drainage of $500 \mathrm{~mL}$ of pus and a pig-tail catheter was left in situ.

After the finding of a liver abscess the patient was transferred to the Department of Infectious Diseases, Copenhagen University Hospital, Rigshospitalet. Abscess material was cultured both anaerobically and aerobically and from the latter
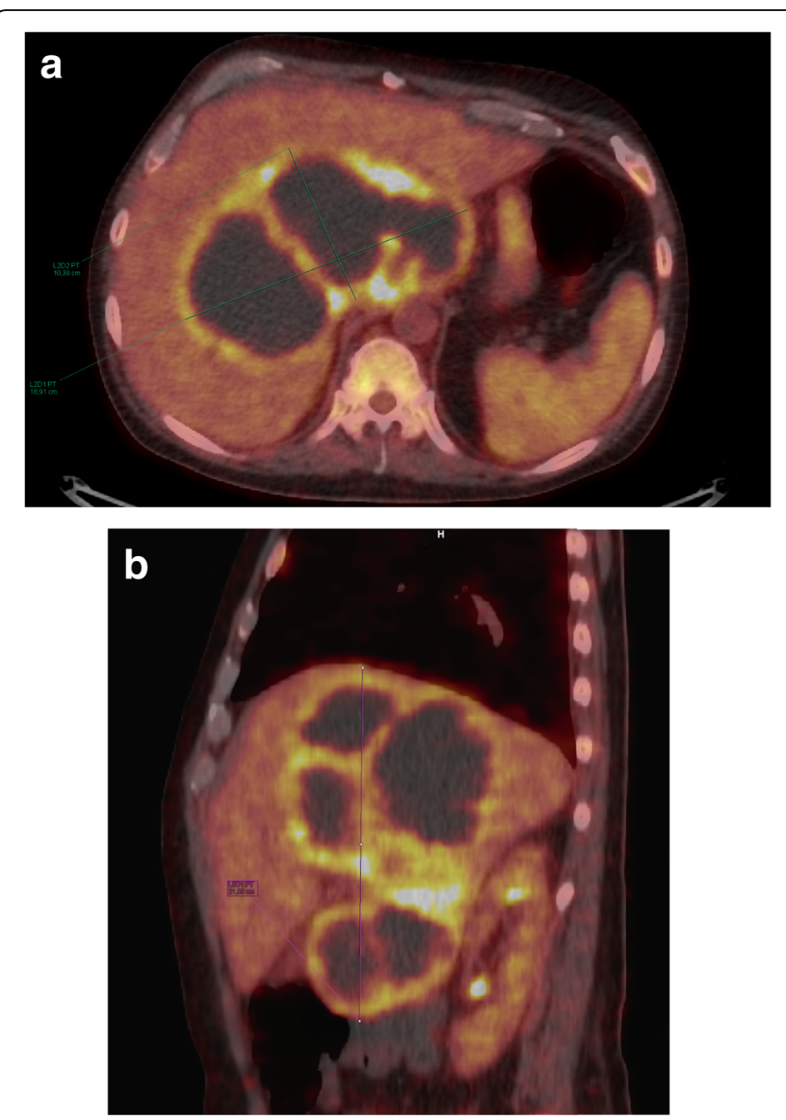

Fig. 1 a Transaxial PET-CT scan demonstrating the large multiloculated liver abscess measuring $10.38 \times 18.98 \mathrm{~cm}$. b Sagittal PET-CT scan showing the large multiloculated liver abscess measuring $21,99 \mathrm{~cm}$ in cranio-caudal dimension

grew Eikenella corrodens. Further blood cultures were collected but remained negative. Because of the finding of a HACEK bacterium, endocarditis was suspected. There were no valvular murmurs at the clinical examination and no other clinical signs of endocarditis, however transthoracic echocardiography showed an excrescence on the aortic valve. A subsequent transoesophageal echocardiography confirmed aortic endocarditis without valve insufficiency.

In the search for the origin of infection, a panoramic dental radiography was performed showing no signs of dental abscesses but extremely poor tooth status, leading to extraction of 10 teeth.

\section{Treatment}

When diagnosed with PLA on PET-CT and after ultrasound-guided drainage, the patient was empirically treated with meropenem, ciprofloxacin and metronidazole. After recognition of the Eikenella corrodens resistance pattern, antibiotic treatment was narrowed to cefuroxime, and metronidazole was continued to cover other potential anaerobic pathogens. Due to a new onset of fevers and subsequent elevation of WBC and CRP, intravenous ciprofloxacin 
was reintroduced and further improvement was observed. The patient was treated with ultrasound-guided abscess aspirations six times (2-7 days intervals) and with pig-tail catheters in between in order to drain different parts of the multiloculated abscess. Antibiotic treatment and ultrasound-guided aspirations in relation to temperature and CRP level are illustrated in Fig. 2. In total, the patient was treated with intravenous therapy for 6 weeks to cover both liver abscess and endocarditis. After discharge, he received high-dose oral antibiotics with amoxicillin and ciprofloxacin for another 2 weeks.

\section{Out-come and follow up}

The patient improved on the combination of antibiotics and continuous liver drainage, fever faded and his appetite returned. At discharge the WBC and CRP were within normal range, alanine aminotransferases was normalized. Alkaline phosphatase remained slightly elevated and he continued to have slight hypoalbuminemia $25 \mathrm{~g} / \mathrm{L}$. On follow-up in the outpatient clinic after 2 months the patient was well and asymptomatic with normalized biochemistry and almost complete regression of the liver abscess on ultrasound.

\section{Discussion and conclusions}

This is the first case report in the literature of cooccurrence of Eikenella corrodens endocarditis and liver abscess. The liver abscess is the largest ever described caused by this bacteria. Reviewing the literature revealed only 12 previous case reports of Eikenella corrodens liver abscess [6-17] and 18 cases of endocarditis [5, 20-37]. The opportunistic pathogen Eikenella corrodens is one of the HACEK bacteria and constitute part of the normal human mucosal flora, predominantly the oropharynx [2]. In this case report, the focus of infection was most likely the oropharynx, as the patient's dental hygiene was very poor. We never isolated the bacteria from the blood, which is not uncommon neither in the case of liver abscesses [38] nor with HACEK endocarditis [4]. Usually, Eikenella corrodens infections are described as part of polymicrobial infections [39], but despite thorough culturing, no other microorganisms were isolated from either pus or blood in our patient.

Patients with PLA often present with fever, nausea and abdominal pain, however it is not uncommon with an unremarkable clinical examination and negative blood cultures [38], which challenges the diagnostic. Our patient had a protracted disease course with malaise, fever, cough and an unintentional weight loss of $7 \mathrm{~kg}$, but never any abdominal pain, and the diagnosis of the liver abscess was not determined until a PET-CT scan was performed. Most of the other case reports of Eikenella corrodens liver abscesses describe a more acute onset of symptoms [9-17]. In contrast Eikenella corrodens endocarditis has been described with a insidious disease course [1] and the time for diagnosis has varied from 1 to 4 months [22].

We treated our patient with broad-spectrum antibiotics after the identification of the liver abscess and he responded well, but when trying to narrow the therapy, WBC and CRP increased, the patient turned febrile, and ciprofloxacin was reintroduced after which the patient improved. Eikenella corrodens is typically resistant to metronidazole, clindamycin and aminoglycosides [17] but susceptible to cephalosporins and fluoroquinolons which is the recommended treatment in Eikenalla corrodens infections. There has been described large variations

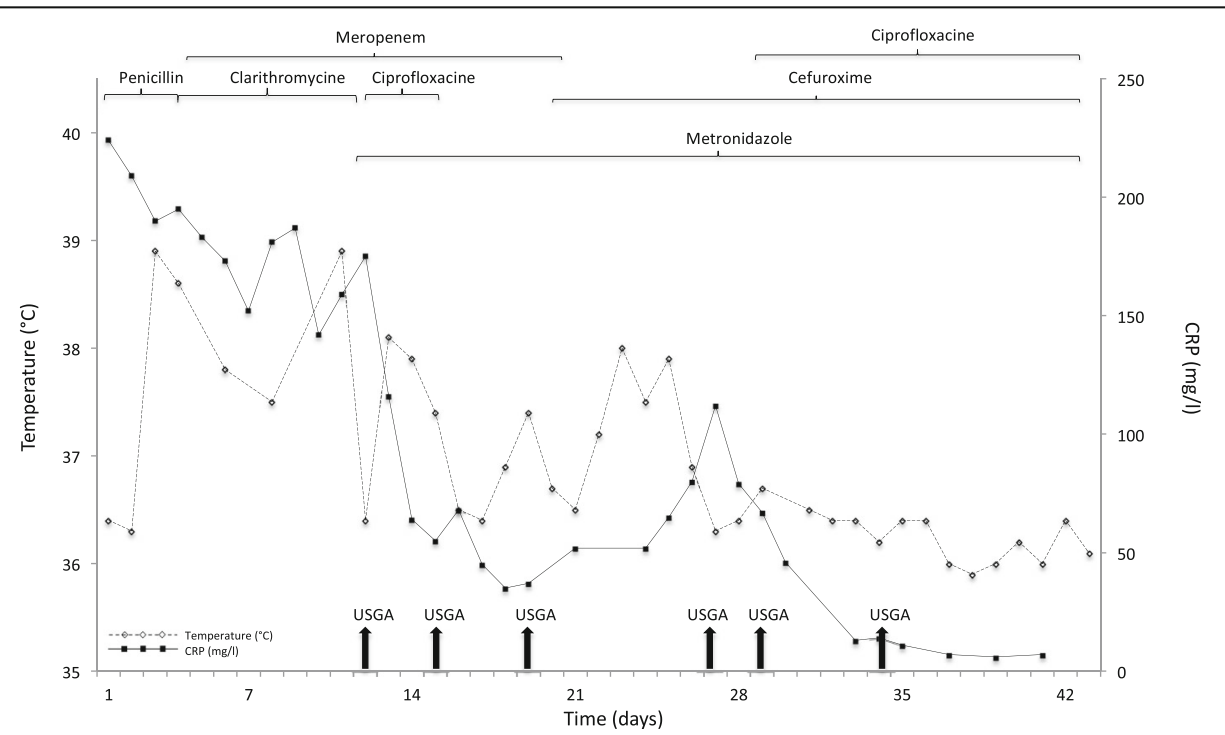

Fig. 2 Treatment with antibiotics and ultrasound-guided aspirations (USGA, vertical arrows) in relation to temperature and CRP from admission to discharge 
between the different generations of the cephalosporins with third generations being much more potent against Eikenella corrodens infections than second and first generations [40]. The observed improvement after reintroduction of ciprofloxacine most likely illustrates that cefuroxime alone is not so potent and that a combination with a fluoroquinolone is a better choice. In order to cover anaerobic pathogens our patient received metronidazole, as other case reports have also suggested [12]. The antibiotic therapy was decided in order to treat both endocarditis and the liver abscess, though the latter needed supplementary drainage. In most previous case reports drainage has only been necessary for a few days, whereas our patients needed a combination therapy with both continuous drainage and aspirations with 2-7 days intervals for almost 1 month on which the abscess decreased in size. To our knowledge our patient had the largest multiloculated abscess with Eikenlla corrodens ever described. In the current literature, Eikenella corrodens has never been described as the cause of both liver abscess and endocarditis, which, therefore, must be considered particularly rare.

Despite of limited pathogenicity, Eikenella corrodens should be considered as a potential pathogen causing liver abscess and a multiloculated lever abscess may require drainage several times and pus should be examined as blood cultures might come out negative. Investigations should include dental inspection and imaging of the abdomen. The finding of Eikenella corrodens, a member of the HACEK group, should cause investigation of endocarditis even in previously healthy patients without obvious clinical signs of endocarditis.

\section{Abbreviations}

CRP: C-reactive protein; Ig: Immunoglobulins; PET-CT: Positron emission tomography-computer tomography; PLA: Pyogenic liver abscess;

USGA: Ultrasound-guided aspirations; WBC: White blood cell count

\section{Acknowledgements}

We would like to thank chief physician Kim Francis Andersen, the Department of Clinical Physiology, Nuclearmedicine and PET, Rigshospitalet, for providing images relevant for publication and Nikolaj Ihlemann, the Department of Cardiology, Rigshospitalet, for assisting on the endocarditis diagnosis.

\section{Funding}

None.

\section{Availability of data and materials}

The data used and analysed during the current study are available from the corresponding author on reasonable request.

\section{Authors' contributions}

ACN admitted the patient when he was transferred to Rigshospitalet, Copenhagen University Hospital, performed the literature review and drafted the manuscript. OV presented the case at a conference in the Department and assisted the literature search and the drafting. HP treated the patient at the local hospital and revised the manuscript. TK assisted the treatment at the University Hospital and provided senior guidance in the writing of the manuscript. All authors read and approved the final manuscript.
Ethics approval and consent to participate

Not applicable.

\section{Consent for publication}

Written informed consent was obtained from the patient for publication of this case report with accompanying images.

\section{Competing interests}

The authors declare that they have no competing interests.

\section{Publisher's Note}

Springer Nature remains neutral with regard to jurisdictional claims in published maps and institutional affiliations.

\section{Author details}

${ }^{1}$ Department of Infectious Diseases, Copenhagen University Hospital, Rigshospitalet, Copenhagen, Denmark. '2Department of Respiratory Medicine, Bispebjerg Hospital, Copenhagen, Denmark. ${ }^{3}$ Department of Cardiology, Copenhagen University Hospital, Rigshospitalet, Copenhagen, Denmark.

Received: 7 March 2017 Accepted: 5 January 2018

Published online: 12 January 2018

References

1. Revest M, Egmann G, Cattoir V, Tattevin P. HACEK endocarditis: state-of-theart. Expert Rev Anti-Infect Ther. 2016;14(5):523-30.

2. Perez Trallero E, Garcia Arenzana JM, Cilla Eguiluz G, de Toro Rios P. Extraoral origin of Eikenella corrodens infection. Lancet. 1988;1(8580):298-9.

3. Das M, Badley AD, Cockerill FR, Steckelberg JM, Wilson WR. Infective endocarditis caused by HACEK microorganisms. Annu Rev Med. 1997;48:25-33.

4. Brouqui $P$, Raoult D. Endocarditis due to rare and fastidious bacteria. Clin Microbiol Rev. 2001;14(1):177-207.

5. Watkin RW, Baker N, Lang S, Ment J. Eikenella corrodens infective endocarditis in a previously healthy non-drug user. Eur J Clin Microbiol Infect Dis. 2002;21(12):890-1.

6. Nagesh KG, Poulose KP, Rao GM. Liver abscess: eikenella corrodens and streptococci. J Kans Med Soc. 1977;78(7):340-2.

7. Abbas SZ, Cunningham R, Wilkinson SP. An unusual polymicrobial liver abscess. J Infect. 2000;40(3):291-2.

8. Bonatti HJR, Stauffer J, Turan N, Goegele H, Sifri CD, Martin K, Hinder R, Nguyen JH. Liver abscess due to Eikenella corrodens, Prevotella meloninogenica, and Lactobacillus spp. following pancreatoduodenectomy: case report and review of the literature. Eur Surg. 2010;41(1):58-64.

9. Chang PS, Ni YH, Lin WT, Lee CY, Chang MH. Isolation of Eikenella corrodens from polymicrobial hepatic abscess: report of one case. Acta Paediatr Taiwan. 1999:40(1):50-2.

10. Arnon R, Ruzal-Shapiro C, Salen E, DeFelice A, Kazlow P. Eikenella corrodens: a rare pathogen in a polymicrobial hepatic abscess in an adolescent. Clin Pediatr (Phila). 1999;38(7):429-32.

11. Hofstad T, Horn A. Isolation of Eikenella corrodens from a liver abscess. Case report. Acta Chir Scand. 1989;155(2):139-40.

12. Jaqua NT, Smith AJ, Shin TT, Jahanmir J. Actinomyces naeslundii and Eikenella corrodens as rare causes of liver abscesses. BMJ Case Rep. 2013;2013: bcr2013009613. doi:10.1136/bcr-2013-009613.

13. Joseph A, Lobo DN, Gardner ID, Iftikhar SY. Eikenella corrodens liver abscess complicated by endophthalmitis. Eur J Gastroenterol Hepatol. 1998;10(8):709-11.

14. Kessler AT, Kourtis AP. Images in clinical medicine. Liver abscess due to Eikenella corrodens from a fishbone. N Engl J Med. 2001;345(23):e5.

15. Massey BT. Eikenella corrodens isolated from a polymicrobial hepatic abscess. Am J Gastroenterol. 1989;84(9):1100-2.

16. Morante AP, Sanjuanbenito A, Mendia E, Giordano PG, Angarita FG. Liver abscess by Eikenella corrodens. Rev Esp Enferm Dig. 2015;107(9):574-5.

17. Quinlivan D, Davis TM, Daly FJ, Darragh H. Hepatic abscess due to Eikenella corrodens and Streptococcus milleri: implications for antibiotic therapy. J Infect. 1996:33(1):47-8.

18. Kaplan GG, Gregson DB, Laupland KB. Population-based study of the epidemiology of and the risk factors for pyogenic liver abscess. Clin Gastroenterol Hepatol. 2004;2(11):1032-8.

19. SC Y, Ho SS, Lau WY, Yeung DT, Yuen EH, Lee PS, Metreweli C. Treatment of pyogenic liver abscess: prospective randomized comparison of catheter drainage and needle aspiration. Hepatology. 2004;39(4):932-8. 
20. Cardoso JN, Ochiai ME, Oliveira MT Jr, Morgado P, Munhoz R, Andretto FE, Mansur AJ, Barretto AC. Eikenella corrodens infective endocarditis. Arq Bras Cardiol. 2005;85(1):63-4.

21. Silpa M, D'Angelo J. Eikenella corrodens infections in drug abusers. Ann Intern Med. 1980;92(6):871.

22. Patrick WD, Brown WD, lan Bowmer M, Sinave CP. Infective endocarditis due to Eikenella corrodens: case report and review of the literature. Can J Infect Dis. 1990;1(4):139-42.

23. Wang'ondu RW, Murray TS. Relapse of polymicrobial endocarditis in an intravenous drug user. Yale J Biol Med. 2011;84(3):321-4.

24. Bigl P, Pavek V, Brezinova L. Eikenella corrodens infection of the oral cavity as a cause of bacterial endocarditis. Czech Med. 1990;13(1):38-42.

25. Burger AJ, Messineo FC, Schulman P, Geller D. Mycotic aneurysm of the sinus of Valsalva due to Eikenella corrodens bacterial endocarditis. Cardiology. 1984:71(4):220-8

26. Decker MD, Graham BS, Hunter EB, Liebowitz SM. Endocarditis and infections of intravascular devices due to Eikenella corrodens. Am J Med Sci. 1986;292(4):209-12.

27. Dorff GJ, Jackson LJ, Rytel MW. Infections with Eikenella corrodens. A newly recognized human pathogen. Ann Intern Med. 1974;80(3):305-9.

28. Fainstein V, Luna MA, Bodey GP. Endocarditis due to Eikenella corrodens in a patient with acute lymphocytic leukemia. Cancer. 1981;48(1):40-2.

29. Geraci JE, Hermans PE, Washington JA 2nd. Eikenella corrodens endocarditis: report of cure in two cases. Mayo Clin Proc. 1974;49(12):950-3.

30. Hansen LA, Salem AG, Edson RS. Eikenella corrodens: an unusual cause of endocarditis in a patient with silent mitral valve prolapse. S D J Med. 1989;42(11):5-8.

31. Heiro M, Nikoskelainen J, Engblom E, Kotilainen P. Eikenella corrodens prosthetic valve endocarditis in a patient with ulcerative colitis. Scand J Infect Dis. 2000;32(3):324-5.

32. Landis SJ, Korver J. Eikenella corrodens endocarditis: case report and review of the literature. Can Med Assoc J. 1983;128(7):822-4.

33. Mahapatra A, Mishra S, Pattnaik D, Patnaik K. Bacterial endocarditis due to Eikenella corrodens: a case report. Indian J Med Microbiol. 2003;21(2):135-6.

34. Marcus HR, Phelps CM. Eikenella corrodens subacute bacterial endocarditis: mixed infection in amphetamine user. N Y State J Med. 1977;77(14):2259-61.

35. Olopoenia LA, Mody V Reynolds M. Eikenella corrodens endocarditis in an intravenous drug user: case report and literature review. J Natl Med Assoc. 1994:86(4):313-5.

36. Shinhar E, Silver J, Yeivin R, Shapiro M. Polymicrobial endocarditis due to Eikenella corrodens and group B beta-hemolytic streptococcus. Isr J Med Sci. 1980;16(6):458-9.

37. Sobel JD, Carrizosa J, Ziobrowski TF, Gluckman SJ. Polymicrobial endocarditis involving Eikenella corrodens. Am J Med Sci. 1981;282(1):41-4.

38. Rahimian J, Wilson T, Oram V, Holzman RS. Pyogenic liver abscess: recent trends in etiology and mortality. Clin Infect Dis. 2004;39(11):1654-9.

39. Sheng WS, Hsueh PR, Hung CC, Teng LJ, Chen YC, Luh KT. Clinical features of patients with invasive Eikenella corrodens infections and microbiological characteristics of the causative isolates. Eur J Clin Microbiol Infect Dis. 2001;20(4):231-6.

40. Coburn B, Toye B, Rawte P, Jamieson FB, Farrell DJ, Patel SN. Antimicrobial susceptibilities of clinical isolates of HACEK organisms. Antimicrob Agents Chemother. 2013;57(4):1989-91.

\section{Submit your next manuscript to BioMed Central and we will help you at every step:}

- We accept pre-submission inquiries

- Our selector tool helps you to find the most relevant journal

- We provide round the clock customer support

- Convenient online submission

- Thorough peer review

- Inclusion in PubMed and all major indexing services

- Maximum visibility for your research

Submit your manuscript at www.biomedcentral.com/submit 